Research Article

\title{
ICT Adoption Impact on Students' Academic Performance: Evidence from Saudi Universities
}

\author{
Wael Sh. Basri ${ }^{1},{ }^{1}$ Jehan A. Alandejani, ${ }^{2}$ and Feras M. Almadani ${ }^{2}$ \\ ${ }^{1}$ College of Business Administration, Northern Border University, Arar, Saudi Arabia \\ ${ }^{2}$ Deanship of Preparatory Year and Supportive Studies, Northern Border University, Arar, Saudi Arabia \\ Correspondence should be addressed to Wael Sh. Basri; wbassri@hotmail.com
}

Received 18 March 2017; Revised 5 November 2017; Accepted 28 November 2017; Published 19 April 2018

Academic Editor: Janine M. Jurkowski

Copyright (c) 2018 Wael Sh. Basri and Jehan A. Alandejani. This is an open access article distributed under the Creative Commons Attribution License, which permits unrestricted use, distribution, and reproduction in any medium, provided the original work is properly cited.

\begin{abstract}
This study investigates and explores the adoption of information communication technology by the universities and the impact it makes on the university students' academic performance. The study also examines the moderators' effect of gender, GPA, and student majors on the relationship between ICT and academic achievement. By using a quantitative research approach and a sample size of 1000 students, data were collected about the ICT adoption in universities and the relative performance of students belonging to four Saudi universities. Structure equation modelling was chosen to determine the validity of the research model. The Analysis of Moment Structures (AMOS), specially used for structural equation modelling and path analysis, was used as the research tool. The findings reveal that there exists a relationship between ICT adoption and academic performance in a conservative environment. An additional finding also stated that ICT adoption resulted in the improvement of the performance of female students more than the male. However, students' IT major was found to be making no impact on students' academic achievement. A discussion of findings, limitations, and suggestions for future research has been provided in the study. Finally, it also provides implications of the current study to the existing knowledge.
\end{abstract}

\section{Introduction}

Information and communication technology (ICT) has become an important source of innovation and improvement of efficiency for many sectors across the globe. In the education sector, particularly, the application of ICT has become a critical part of the learning process for university students both outside and inside the classroom setting. The government and other stakeholders in the education sector such as university management and researchers have invested millions of dollars to adopt ICT in the education system during the last two decades [1]. Most universities that have fully adopted ICT have recorded immense advancement in the application of ICT for the improvement of learning methods, teaching, research, and development. It is, however, not clear what impact the ICT applications have on the performance and achievement of students.

ICT adoption in the current study is understood as a gradual switching over to automation of the educational process not only in administrative activities like students admission, registration, and evaluation but also developing a customized learning management system (LMS) and transferring all the courses and the related data onto it. In the sampled universities for this study, Blackboard is the LMS that has been adopted. The faculty members as well as the students are allowed access to the LMS along with its all services and the specialized online learning tools. The adoption of LMS across Saudi Arabia has facilitated the educational processes to a great extent.

The students' academic performance refers to the enhancement of the students' current state of knowledge and skills reflected in their GPA and also in the formulation of their personality and academic growth from lower levels of study to higher levels. The rationale of studying academic performance in the context of ICT adoption is to present a significant relationship that exists between the two variables.

This study is based on the data collected from four universities of Saudi Arabia, two of which, namely, King 
Abdulaziz University (KAU) and Damam University (DU), had fully adopted ICT in the educational processes while the other two, namely, Northern Border University (NBU) and Baha University (BAU), are in the process of adopting the ICT in their system. The rationale behind choosing these universities, which differ in size, geographical locations, number of students, number of courses, and also in terms of IT adoption is to frame a comprehensive research model with the possibility to generalize its findings.

Numerous studies have been undertaken to investigate the relationship between ICT and students' performance; however, these studies have not been able to establish precisely the impact of ICT on students' performance. These studies have posed two core challenges: first, it is difficult to determine the performance of students since the common approach used by many researchers accredits the curriculum responsible for the performance achievement in terms of grade [2]. However, Ali et al. [3] and Rose and Kadvekar [4] criticize these studies, blaming them of adopting a narrow approach, and suggest an alternative approach to consider the influence of ICT on students' attitude, competency, and skills in addition to curriculum. This approach, according to the authors, has been campaigned as more extensive approach capable of yielding more accurate results compared with the narrow approach. However, this extensive approach demands a more comprehensive and complex strategy to focus and observe the labor market.

The second challenge lies in technological changes that are rampant where it is difficult to treat their impact different from their environment. This aspect therefore makes such research attract high contention on the ground that rapid changes in technology would render the used parameters ineffective; therefore, no conclusive results can be drawn from such studies [2]. Furthermore, many studies conducted on this subject are based on scientific studies of comparison. These studies establish that adoption of ICT technology in institutions of learning could improve the respective institution. Additionally, most of the studies have focused on cognitive results, including a few recent studies that have encountered effective results and a positive attitude towards ICT development.

Based on the identified research gaps and the problem statement, a need is felt to investigate the adoption of ICT in university education programs and examine its impact on the performance of the students. In this regard, the proposed research will carefully evaluate the manner and the extent to which universities have adopted the use of ICT and how the adoption of ICT has consequently made an impact on the performance of students. The proposed research will also identify key factors that contribute to performance of university students and how these factors are influenced by information communication technology.

The researcher seeks to meet the following research objectives in this study:

(a) To evaluate the extent to which the universities have adopted ICT

(b) To determine the relationship between ICT adoption and the performance of the university students (c) To find out the impact of ICT adoption on universities, in general, and on students' performance, in particular

\section{Literature Review}

This section presents a recap of the findings from earlier studies regarding the adoption of ICT in university education and its impact on the performance of university students. There have been various studies carried out to investigate the relationship between ICT and quality of education. These studies have focused on various such factors that have been influenced by ICT, but very few studies evaluate the impact of ICT adoption on the performance of university education. Similarly, these studies also give mixed findings about the impact of ICT on the university students' performance.

For instance, Ellis and Loveless [5] indicate that higher education pedagogy can neither be isolated from academic achievement nor from the teaching process and innovation. The study affirms that the potential role of information and communication technology in higher education cannot be overlooked. Chan et al. [6], in another study, make a similar observation and assign great significance to the critical function of ICT in democratizing the university education and meeting new and dynamic demands of graduate students.

In a similar study, Sari and Mahmutoglu [7] observe that in order to bring a change in teaching methodology in a university, a paradigm shift is required that would recommend adoption of student-centered approaches. The new methodology, according to the authors, should aim at making the student an active element in the learning process, rather than passive through an adequate and effective guidance from the tutorial team. Likewise, Iniesta-Bonillo et al. [8] find out that the use of information and communication technology is significant in placing students in an active position and in enhancing the effectiveness and efficiency of the tutorial support.

As a result, all relevant stakeholders involved in higher education have made tremendous efforts to ensure adoption of ICT in their university education system. According to a report published by the United Nations Educational, Scientific and Cultural Organization (UNESCO) Institute of Statistics (2013), governments and university managements globally have heavily invested in adopting of information technology in their education systems. Overall, numerous attempts, both theoretical and empirical, have been made in a bid to evaluate the impact of ICT adoption in the education system [9].

The recent research frameworks for investigating the adoption of ICT in higher education have focused only on aspects related to performance in education. Such performance indicators have been utilized in these frameworks to establish how variables such as infrastructure and availability of other resources contribute to the impact. A few studies have also taken into account the institutional culture and implementation process at both initial and advanced levels [9]. The advanced levels, being national and international 
levels, have recorded a remarkable progress evidenced in the form of establishment of policies and regulations that support the integration of ICT in the education system [10]. The university administrators and faculty too look for the most appropriate approaches to harness the application of ICT in improving their teaching methods culminating into improvement of the students' performance. Nonetheless, tangible achievement of all such efforts that should be demonstrated as results fuelled by the ICT or as impact of its adoption is not easily identifiable.

Additionally, there also exist numerous and significant studies that evaluate and track the efficiency of the ICT application and its impact on education. For instance, the Second Information Technology in Educational Study (SITES) is a study supported by the International Association for the Evaluation of Education Achievement (IEA) which has evaluated and described how ICT has successfully been applied across 26 countries globally [11]. This study seeks to ascertain how school administrations, faculty, and ICT teams deploy computers or ICT devices on various platforms. Although the study does not focus on the impact of ICT on the achievement of students, it approaches the subject under study from the perspective of teachers and their perception about the impact of ICT on students' performance [12]. Similarly, Cruz-Jesus et al. [13] analyze several studies related to the impact that ICT has made on educational institutions in Europe. Their findings indicate that there is a limited and incomparable evidence of impact of ICT adoption on students' performance. Irrespectively, none of these studies have been able to provide substantive findings to indicate that ICT adoption has positive impact on students' performance. Further, each study has used a unique methodology and approach making the comparison of the results between the countries under study more complicated.

There are several other research studies carried out to assess the impact of ICT in the domain of education. References [14-17] Solar et al. [18] have argued that adoption of ICT enhances the quality of learning and improves the quality of education. This is consistent with the study by Gallego et al. [19] who argue that, for a successful improvement of the quality of education, a country needs implementation of ICT policies and regulations that must be effective and vigorous at all levels. Babaheidari and Svensson [20] in another study make a different conclusion that the impact of ICT on learning outcomes is not clear. Lin et al. [21] point out that there is no evidence of any strong impact of the application of ICT in education. Likewise, Wastiau et al. [22] indicate that application of ICT in education achievement has positive effects while Venkatesh et al. [23] find out that there exist no actual effects of ICT in education since all research is based on the socioeconomic background of students and embedded characteristics of the school. Such mixed results from previous studies therefore confirm that there is inadequate empirical evidence of the ICT impact on education, and also, there is an absence of well-developed and reliable theoretical studies to support the benefits resulting from ICT implementation.

A few other scholars who have investigated the topic at a national level have used a qualitative approach to determine the efficiency and effectiveness of the student's performance accruing from the adoption of ICT. Macharia and Pelser [24], for instance, investigated the education efficiency in Africa, while Wastiau et al. [22] conducted a similar research in Europe. All these studies have presented a mixed result about the relationship between the adoption of ICT and the performance of university students. They have also created a research void since none of these studies has considered such variables as ICT adoption in relationship to students' academic performance with students' GPA or gender or their IT major as dependent or moderating variables. Similarly, there are studies on students' academic performance, but hardly any study has construed it as the impact of the ICT adoption in the university education system. This amounts to the research gap that this study aims to fill up.

Based on the literature review, a research model was prepared to exhibit the relationship between the independent variable, the dependent variable, and the three moderating variables of this study (Figure 1).

Figure 1 displays this research model where ICT adoption is the independent variable (IV) and the students' academic performance is the dependent variable (DV). The relationship between both IV and DV may differ for each of the three moderating variables (MVs), students' GPA, gender, and students' IT major. This has become the basis for the formulation of each hypothesis since the relationship between IV and DV gets affected or moderated with the value of MV of the study. In this kind of relationship, the MV itself never gets affected but specifies that the relationship between IV and DV differs each time MV interacts with their relationship.

Most quantitative research studies focus on the relationship between an independent variable $X$ and a dependent (outcome) variable $Y$. Statistical effects such as correlation coefficient, odds ratio, and regression coefficient are also calculated on the effects between $X$ and $Y$. However, in the current study, there are three moderating variables too, namely, students' GPA, gender, and students' IT major, besides $X$ and $Y$. Therefore, the number of possible relations among the variables have increased substantially as shown in the below hypotheses.

\section{Hypotheses of the Study}

Based on the research model (Figure 1), the hypotheses are stated as follows:

(1) ICT adoption in the sampled universities has yielded not only administrative benefits but also resulted in enhancing the students' academic performance. With the introduction of Blackboard, the online learning management system (LMS), the faculty, and the students have come closer in their interactions. The study of courses, evaluation, and overall learning has been much better than previous years. Hence, hypothesis $1\left(\mathrm{H}_{1}\right)$ frames as follows:

$H_{1}$ : The ICT adoption has a significant relationship with student's academic performance. 


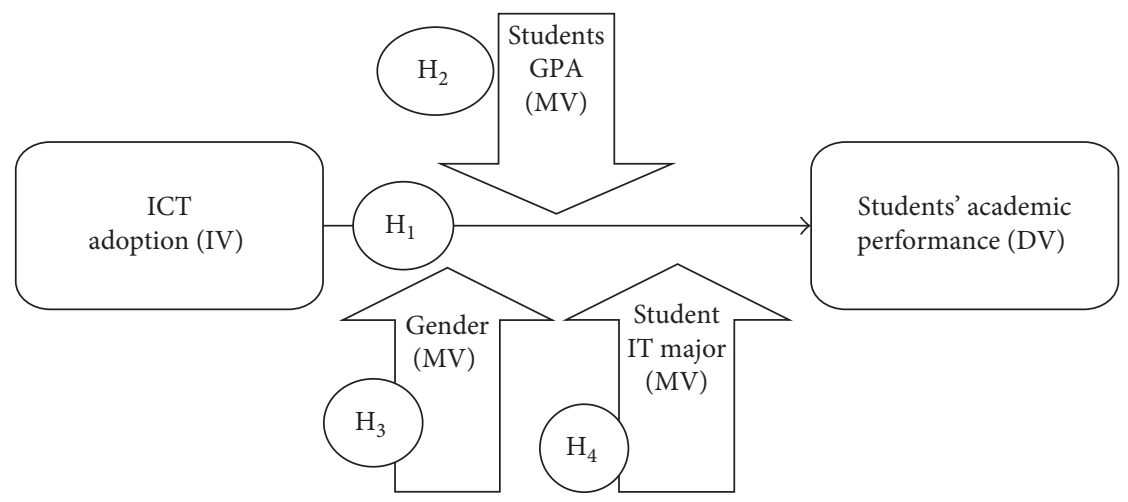

FIgURE 1: The research model.

(2) With the introduction of Blackboard, the online learning management system, the faculty are able to develop teaching tools, online exercises, and even midterm exams in a few cases. This has resulted in an increase in students' GPA. The university too recognized this increase and accelerated their ICT services by increasing benefits and adding new features such as uploading class seminars, audios, and videos. Thus, students have an access to a greater amount of ICT material. This has also resulted in the increase of the ICT usage on average basis. Hence, hypothesis $2\left(\mathrm{H}_{2}\right)$ runs as follows:

$\mathrm{H}_{2}$ : Student GPA has a positive influence on the relationship between ICT adoption and student academic performance.

(3) A conservative environment prevails in all universities across Saudi Arabia which puts restriction on boys and girls to study together, without exception. Besides, girl students also have a restriction to attend some of the seminars, workshops, and other such inhouse academic activities. However, in terms of ICT usage, there is no such restrictions. Hence, it has been noticed that girls depend upon the ICT services more than the boys. The number of usage of ICT and access to the LMS is higher among the girl students than the boys. This necessitated the increase in services and processes equally for the girls during the ICT adoption processes. Hence hypothesis $3\left(\mathrm{H}_{3}\right)$ runs as follows:

$H_{3}$ : Students' gender significantly affects the relationship between ICT adoption and students' academic performance.

(4) A lot of students in universities study IT as a major and have an access to the latest software and hardware equipment, resources, and technological gadgets. Many of these students will also choose IT as their career option. Hence, a major responsibility of the university is to provide a full support to these IT aspirants in realizing their career dreams as well as proving them opportunities to acquire complete IT awareness and skills. The university therefore has to make an extra effort in the application of ICT in the education system. Hence, hypothesis $4\left(\mathrm{H}_{4}\right)$ runs as follows:

$H_{4}$ : Student major affects the relation between ICT adoption and student academic performance.

\section{Methodology}

The methodology for this study was prepared according to the procedures recommended by Basri and Suliman [25], who suggested quantitative techniques and tools such as questionnaires for data collection. Data collection through questionnaire enables an objective analysis of the hypotheses under study. The researcher can conveniently enter the statistical findings of the closed ended questionnaire in a data analysis software in order to quantify the results. Another rationale for adopting quantitative measures for an empirical study like the current one is that the mandatory use of the quantitative tools or software in the form of columns and tables would usefully supplement and extend the research analysis [26]. Also, the analysis based on statistical data is both validated and reliable since there is no personal bias and is the evidence of an objective research analysis.

4.1. Sampling and Population. The study engaged respondents from four universities, two of which, namely, King Abdulaziz University (KAU) and Damam University (DU), had fully adopted ICT in the educational processes while the other two, namely, Northern Border University (NBU) and Baha University (BAU), were in the process of adopting the ICT in their system. The study encompasses a sample size of 1000 respondents, 250 students from each university. The students were grouped into two categories of male and female for the ease of data analysis. The purposive sampling technique assisted in getting a personal bias-free data because the respondents were interested to participate in the study. Difficulties arose in an attempt to administer the questionnaires as well as hold faculty interviews as both data collection methods were time-consuming, and the universities were also geographically apart at long distances.

4.2. Data Collection Tools and Instruments. This study has made use of a close-ended questionnaire in order to collect 
data from selected university students who had access to ICT applications. The content validity of the items of the questionnaire was conducted by two subject experts. The data from the teachers were collected thorough an interview with open and closed ended questions conducted on-site.

4.3. Data Analysis. After the completion of data collection, the researcher analyzed the data to check whether there were identifiable errors, inconsistencies, and incompleteness. Structural equation modelling (SEM) technique was used to measure the extent of university adoption of ICT and the impact that this adoption had on the academic performance of students. The software application AMOS-SPSS was used to establish the significant variations in the moderating variables that influenced students' academic performance in each category of respondents [27]. SEM provides a very general as well as convenient framework for statistical analysis that includes several traditional multivariate procedures such as regression analysis, factor analysis, path analysis, discriminant analysis, and canonical correlation [28], as a special case.

SEM was developed as a result of the limitations in the ordinary least squares, particularly when dealing with latent constructs [27]. SEM follows a confirmatory hypothesis testing approach to multivariate analysis of a structural theory, which specifies causal relations among multiple variables $[28,29]$. The measurement model in SEM is evaluated through confirmatory factor analysis (CFA), a special form of factor analysis, most commonly used in social research which allows an indicator to load on multiple factors if the indicator is believed to measure several latent constructs [29]. In addition, it allows residuals or errors to correlate if the indicators are believed to measure a different construct other than the latent constructs included in the model.

Analysis of Moments Structures (AMOS) is also one of the latest software developed for SEM employed to analyze the research data. AMOS Basic allows users to specify models from equation statements [29]. AMOS Graphic allows users to specify models by diagram drawing. It is used to model as well as to analyze the interrelationships among latent constructs effectively, efficiently, and accurately. According to Awang [27], an important advantage of AMOS Graphic lies in its ability to compute simultaneously the multiple equations of interrelationships in a model. Thus, AMOS allows users to create path diagrams using either drawing tools or by writing equations or typing commands.

Out of the 1000 questionnaires distributed, over 80 percent returned. Out of the total questionnaires received back, only 629 students have completed them correctly. The rest are discarded and excluded from the analysis. Among the respondents, there are 389 girls (61\%) and 240 boys (39\%). A majority (34\%) of respondents belong to social science major. Sixty percent of the respondents have GPA between 3.0 and 4.0 on a 5-point scale. Over half of the total respondents are in their third year of study of the 4-year program. Approximately two-thirds of the respondents have some experience with technology, and they use computer
TABLE 1: Sample description.

\begin{tabular}{lcccccc}
\hline Total & KAU & DU & NBU & BAU & Girls & Boys \\
\hline 629 & 200 & 124 & 210 & 95 & 389 & 240 \\
$100 \%$ & $32 \%$ & $20 \%$ & $33 \%$ & $15 \%$ & $61 \%$ & $39 \%$ \\
\hline
\end{tabular}

TABLe 2: Descriptive statistics for the independent variable ICT adoption (the model Cronbach's alpha 0.780).

\begin{tabular}{lcc}
\hline Statements & Mean & $\begin{array}{c}\text { Std. } \\
\text { Dev. }\end{array}$ \\
\hline $\begin{array}{l}\text { I should use ICT services through } \\
\text { my computer. }\end{array}$ & 2.63 & 0.85 \\
$\begin{array}{l}\text { My school supports ICT in my university. } \\
\begin{array}{l}\text { It is easy for me to observe others } \\
\text { (peers) using ICT in my university. }\end{array}\end{array}$ & 2.33 & 0.58 \\
\begin{tabular}{l} 
Average score \\
\hline
\end{tabular} & 3.52 & 1.10 \\
\hline
\end{tabular}

application more than two hours a day. Fifty percent of these respondents maintain accounts on social media platform. Table 1 presents a few details about the sample respondents who finally participated in the research.

Table 2 presents Cronbach's alpha $\alpha$ reliability indicators as 0.80 , which describes the model as well fitted, with good internal consistency The mean score of the respondents is reasonably high with the value of $2.82(\mathrm{Std} .=0.84)$. This implies that the ICT adoption affects the students' academic performance. The significance of reliability is satisfactory and cannot be modified further (Table 2). A few statements have been exemplified to depict the kind of data extracted from the respondents. The statements show the personal as well as school's engagement and the penetration of ICT activities in student's routine as well as with peers.

The study has used incremental model fit indices in order to measure the increase in fit relative to a baseline model, which is a model in which all observed variables are not correlated. They include normed fit index (NFI), relative noncentrality index (RNI), Tucker-Lewis index (TLI), and comparative fit index. Values $\geq 0.90$ are required to accept a model, whereas values $\geq 0.95$ are indicative of good fit $[28,29]$. On the other hand, absolute fit indices include goodness-of-fit index (GFI) and adjusted GFI (AGFI), standardized root mean square residual (SRMR), and the root mean square error of approximation (RMSEA) [28-30]. A good model-data fit is demonstrated by high values of GFI and AGFI together with low values of SRMR and RMSEA. According to $\mathrm{Hu}$ and Bentler [30], RNI (OR CFI) $\geq 0.95$, SRMR $\leq 0.08$, and RMSEA $\leq 0.06$ are indicative of good model-data fit. SRMR and RMSEA are used to assess how well a model approximates the true model. Table 3 presents the acceptable values of this model, evidence of a perfect fit of the research model.

The result of hypotheses testing the relationships among the variables and the mediators involved are summarized in Figures 2 and 3 and Table 4. The figures show that out of the whole model relationship, three hypotheses were supported. In this study, it is the linear direction where the depiction of 
TABle 3: Model fit acceptable values.

\begin{tabular}{lccccc}
\hline NFI & RNI & GFI & TLI & SRMR & RMSEA \\
\hline 0.96 & 0.90 & 0.95 & 0.93 & 0.05 & 0.03 \\
Acceptable & Good & Acceptable & Acceptable & Acceptable & Acceptable \\
\hline
\end{tabular}

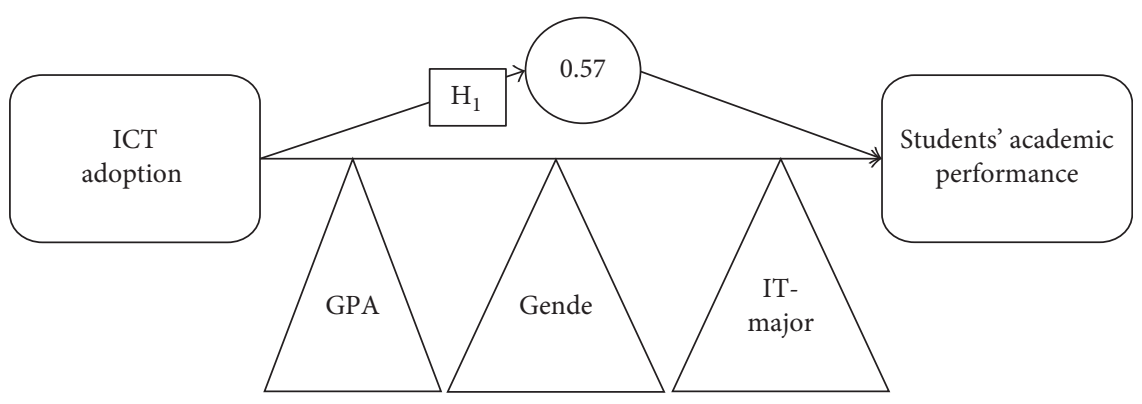

FIgURE 2: The relationship between IV and DV without the moderators.

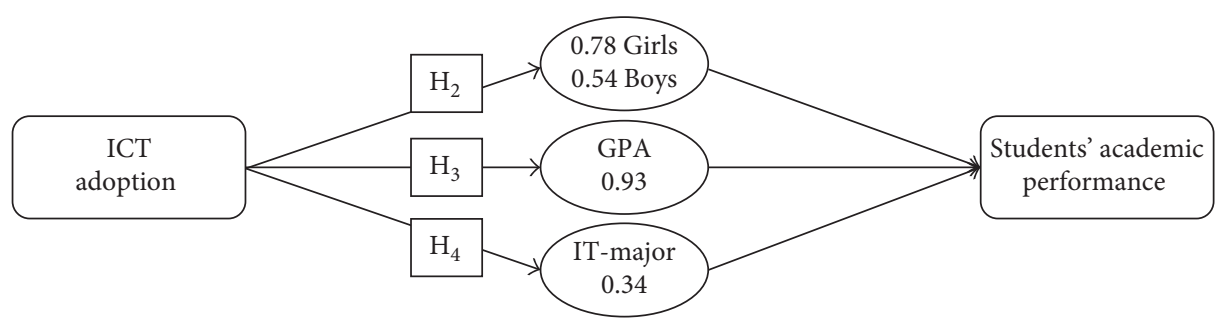

Figure 3: Moderators' effect on the relationship between IV and DV.

TABLE 4: Regression weight and hypothesis test.

\begin{tabular}{lccccc}
\hline & & The relation & Moderator & Regression weight & Hypothesis \\
\hline ICT adoption & $\rightarrow$ & Students' academic performance & All & $\mathbf{0 . 5 7}$ & Supported \\
ICT adoption & $\rightarrow$ & Students' academic performance & Gender & $\mathbf{0 . 7 8}$ & Supported \\
ICT adoption & $\rightarrow$ & Students' academic performance & GPA & $\mathbf{0 . 9 3}$ & Supported \\
ICT adoption & $\rightarrow$ & Students' academic performance & IT major & $\mathbf{0 . 3 4}$ & Not supported \\
\hline
\end{tabular}

1 is the max value same direction; -1 is the max value in the opposite direction; 0.5 to -0.5 not supported; $0.57,0.78$ and 0.93 high association; 0.34 no association.

all variables, IV, DV, and MVs, are entirely linear (Figures 2 and 3). In such situations where interrelationships between variables is ascertained and if all variables are found to be linear, that is, moving in the same direction, it is recommended that the model must be permanently established as a default model. If a single nonlinearity is detected and if the model experiences any nonlinear or reverse movement of variables, the effectiveness of the Assume Model will cease. Figure 2 presents a linear influence of the independent variable up to the dependent variable of the model without any discrepancy created by any moderator. Similarly, when moderators are a part of the analysis, the linear influence passes through the moderators (Figure 3). Both figures present the standardized regression weight $(0.57)$ as calculated in the interrelationship of the variables which is significant of the relationship between the IV and the DV.

Table 4 shows that first three hypotheses, $\mathrm{H}_{1}, \mathrm{H}_{2}$, and $\mathrm{H}_{3}$, having the regression weight more than 0.5 are supported while the fourth hypothesis, $\mathrm{H}_{4}$, is not supported. Table 4 findings also present a good relationship between ICT adoption and students' academic performance, which is consistent with the study reported earlier of Iniesta-Bonillo et al. [8]. The findings are also in congruence with those of other similar studies $[14,16,17]$ that too claim that the adoption of ICT improves the quality of learning outcomes.

Each of the hypotheses of this study has thus been tested and found supported except the fourth hypothesis. The overall involvement and the overwhelming response to ICT adoption making an impact on the academic performance is evident enough to construe hypothesis 1 . Secondly, in spite of the conservative environment as stated in the hypothesis statement above, the findings suggest that ICT adoption is more likely to improve the academic performance of girl students more than boys. Thirdly, a major finding of this study is that GPA has a very strong effect on the relationship between ICT adoption and students' academic performance. 
When applied to real situations, and as stated in the hypothesis statement, this particular finding suggests a gradual increase of GPA due to the adoption of ICT in teaching and learning. The use of Blackboard, the online learning management system, has further facilitated the teachers as well as students. The university is aware of this increase and therefore gradually excels in their ICT services in the form of additional and better services and features. Surprisingly, this research did not detect any evidence of student major-IT making any effect on the relationship between ICT adoption and students' academic performance.

Further statistical tests reveal that over fifty percent of respondents consider ICT applications very useful, while very few participants (4\%) indicated that they use ICT application all the time to do their homework. In addition, under two-thirds of the participants (64\%) admitted that they use smart phone and at least one social media platform to consume their time; about fifteen percent of this number also indicated that they take the help of the social media platform to complete their homework. These findings can be attributed to the conservative culture where common man lacks recreation and entertainment centers like theatres, and social media only remains a platform to recreate and consume time. The findings of this research also contribute to the existing knowledge of the process of ICT adoption in universities and its impact on students' academic performance. The research has also shed light on the relationship between the use of ICT and learning outcomes.

\section{Recommendation and Conclusion}

The findings of this study shall prove useful to the university administration and other parties involved in framing ICT policies for higher education. This study can be used as a reference point to understand that students wishing to enroll for a course in a university finalizes his or her decision based on the level of ICT application present in that university. Last but not least, this study will also act as a jumpstart for other researchers who may like to conduct further research on this topic in future.

Information communication technology (ICT) is among the latest innovations that has revolutionized various operations in the world [31]. It is particularly important in the field of education since it has recently created such platforms and opportunities that have facilitated to some extent the acquisition of knowledge. This phenomenon has been highlighted in this study which indicates how students view ICT as a component of their study program. From the results of the questionnaire, it has been evident that a majority of the respondents value ICT, and each of them feels that they should have the gadgets to be able to adopt ICT more closely.

The study also mentions that a large number of students lack IT gadgets like smart phones and laptops. The reason is both the cost of gadgets and the internet accessibility. The public servers, besides the high cost, are very slow in speed which makes it difficult to utilize ICT platforms on a regular basis. Truly speaking, gadgets such as smart phones and laptops are critical in the access of ICT facilities and search information on the internet. The study also reveals that more than fifty percent of the students keep accounts on social media. This indicates that ICT performs a role more than academic for most university students. Besides searching for information from the internet, these university students make use of ICT for communication and social connections with friends and relatives. This explains why it is a major booster to academic performance of the students in the university. Often the same students can use ICT to facilitate discussions and feedback on academic matters from teachers, seniors, and colleagues. This kind of interaction is necessary to improve their study and research skills.

Another revelation of this study was that students who score higher grades in GPA are more interested in ICT than their colleagues who score lower grades. This is likely because ICT demands some basic knowledge for anyone to embrace it. Brighter students are therefore more likely to embrace ICT. Furthermore, ICT requires concentration of the participants, and this makes people to remain brighter to embrace the technology. It was also revealed in this study that social science students readily adopt ICT more than their other counterparts. This is because most of their courses involve social networking, and ICT becomes a major factor in regulating the social interactions. It is necessary to consider the fact that social sciences bring people together, and ICT too, through social networking, brings people closer and breaks the geographical barriers that hinder communication.

An interesting finding of this study states that there has been an increased use of ICT particularly to search for information related to studies. Adoption of ICT therefore is very high among the university students as majority (more than two-thirds) use ICT at least for two hours in a day. Hence, there is need to offer full support to students' access of ICT as it has the potential to improve their academic performance. At the same time, this has also been observed in this study that a majority of the students who use the ICT for academic purposes are also involved in the use of social media which consumes a lot of their time. This is consistent with the findings of Sánchez et al. [17]. Care should be taken by these students to create a balance between constructive use of ICT and ordinary social networking [17]. From the study, there is also a strong indication that, in terms of gender, females have adopted ICT more than their male counterparts. The study thus hints that female students are capable of making quicker communication using their smart phones as compared to male students. This concludes that social networking or the social networks are frequented by females more than males. ICT has also made it possible for female students to participate in activities that they were not able to do on other platforms or occasions due to the restrictions for the females in Saudi society.

The adoption of ICT by students who have opted IT as their major are not supported in this study. This is probably because all the students who take IT as a major are always in contact with ICT or working in ICT environment. They therefore view ICT not as a technology but as a course. In practice, it is known that those who take IT as a major are in constant contact with technology. They use it on daily basis; however, a few may face the challenges due to the complexity 
of the subject when they look at it from the academic perspective. However, non-IT counterparts use ICT more to connect with their friends, relatives, and instructors using social networks. Hence, it can be inferred with this finding that a course opted by a university student may not determine the adoption of the technology by them for academic purposes alone. It is recommended that a study should be conducted to examine the perception and behavior of such students who are not taking ICT as a course. Though they may not have opted for IT as a major, they use ICT to conduct their research to prepare their graduation projects or solve the home assignments. It is also recommended that all students may be told about the real value and utility of ICT. This is because, in many institutions of higher learning, the use of ICT such as internet search engines has replaced library. The students who fail to get information from the library get it from internet research.

This study also recommends considering the perception of instructors at the universities. Questionnaires must be administered on lecturers and other administrative officers to showcase the usefulness of ICT in university education. For the lecturers who contribute to the academic well-being of students, ICT can play a critical role in aiding the process of preparing classroom instructions.

Last but not least, in order to appreciate the role of ICT in university education, it is necessary to involve all its functionaries in ICT. This study therefore recommends that all the parties should be involved in a study sequel and understand the components of ICT that are relevant to their respective functional unit or department. The current study was limited in time and geographical and physical environment, therefore it could not study other variables like use of ICT in building a career for students, role of ICT in campus-industry connect programs, and field training. Further work is therefore required to investigate all these areas.

\section{Conflicts of Interest}

The authors declare that they have no conflicts of interest.

\section{References}

[1] J. E. Lawrence, "Examining the factors that influence ICT adoption in SMEs: a research preliminary findings," International Journal of Technology Diffusion (IJTD), vol. 6, no. 4, pp. 40-57, 2015.

[2] J. S. Fu, "ICT in education: a critical literature review and its implications," International Journal of Education and Development using Information and Communication Technology (IJEDICT), vol. 9, no. 1, p. 112, 2013.

[3] F. Ali, Y. Zhou, K. Hussain, P. K. Nair, and N. A. Ragavan, "Does higher education service quality effect student satisfaction, image and loyalty? A study of international students in Malaysian public universities," Quality Assurance in Education, vol. 24, no. 1, pp. 70-94, 2016.

[4] A. Rose and S. Kadvekar, "ICT (information and communication technologies) adoption model for educational institutions," Journal of Commerce and Management Thought, vol. 6, no. 3, p. 558, 2015.
[5] V. Ellis and A. Loveless, ICT, Pedagogy and the Curriculum: Subject to Change, Routledge, London, UK, 2013.

[6] D. Chan, A. Bernal, and A. Camacho, "Integration of ICT in higher education: experiences and best practices in the case of the University of Baja California," in Proceedings of the Edulearn13, pp. 1040-1049, Barcelona, Spain, 2013.

[7] A. Sari and H. Mahmutoglu, "Potential issues and impacts of ICT applications through learning process in higher education," Procedia-Social and Behavioral Sciences, vol. 89, pp. 585-592, 2013.

[8] M. A. Iniesta-Bonillo, R. Sánchez-Fernández, and W. Schlesinger, "Investigating factors that influence on ICT usage in higher education: a descriptive analysis," International Review on Public and Nonprofit Marketing, vol. 10, no. 2, pp. 163-174, 2013.

[9] D. Castillo-Merino and E. Serradell-López, "An analysis of the determinants of students' performance in e-learning," Computers in Human Behavior, vol. 30, pp. 476-484, 2014.

[10] S. N. Attuquayefio and H. Addo, "Using the UTAUT model to analyze students' ICT adoption," International Journal of Education and Development using Information and Communication Technology (IJEDICT), vol. 10, no. 3, p. 75, 2014.

[11] J. Voogt, G. Knezek, M. Cox, D. Knezek, and A. ten Brummelhuis, "Under which conditions does ICT have a positive effect on teaching and learning? A call to action," Journal of Computer Assisted Learning, vol. 29, no. 1, pp. 4-14, 2013.

[12] A. M. Croteau, V. Venkatesh, A. Beaudry, and J. Rabah, "The role of information and communication technologies in University Students' learning experience: the instructors' perspective," in Proceedings of the 48th Hawaii International Conference on System Sciences (HICSS'2015), pp. 111-120, IEEE, Kauai, HI, USA, January 2015.

[13] F. Cruz-Jesus, M. R. Vicente, F. Bacao, and T. Oliveira, "The education-related digital divide: an analysis for the EU-28," Computers in Human Behavior, vol. 56, pp. 72-82, 2016.

[14] H. Abdullahi, "The role of ICT in teaching science education in schools," Journal of Educational and Social Research, vol. 3, no. 9, p. 127, 2013.

[15] K. Kreijns, M. Vermeulen, P. A. Kirschner, H. V. Buuren, and F. V Acker, "Adopting the Integrative Model of Behaviour Prediction to explain teachers' willingness to use ICT: a perspective for research on teachers' ICT usage in pedagogical practices," Technology, Pedagogy and Education, vol. 22, no. 1, pp. 55-71, 2013.

[16] H. M. Sabi, F. M. E. Uzoka, K. Langmia, and F. N. Njeh, "Conceptualizing a model for adoption of cloud computing in education," International Journal of Information Management, vol. 36, no. 2, pp. 183-191, 2016.

[17] R. A. Sánchez, V. Cortijo, and U. Javed, "Students' perceptions of Facebook for academic purposes," Computers \& Education, vol. 70, pp. 138-149, 2014.

[18] M. Solar, J. Sabattin, and V. Parada, "A maturity model for assessing the use of ICT in school education," Educational Technology \& Society, vol. 16, no. 1, pp. 206-218, 2013.

[19] J. M. Gallego, L. H. Gutiérrez, and S. H. Lee, "A firm-level analysis of ICT adoption in an emerging economy: evidence from the Colombian manufacturing industries," Industrial and Corporate Change, vol. 24, no. 1, pp. 191-221, 2014.

[20] S. M. Babaheidari and L. Svensson, "Managing the Digitalization of Schools: an exploratory study of school principals' and IT managers' perceptions about ICT adoption and usefulness," in Proceedings of the E-Learn: World Conference on E-Learning in Corporate, Government, Healthcare, and Higher 
Education, vol. 2014, no. 1, pp. 106-113, New Orleans, LA, USA, October 2014.

[21] C. Y. Lin, C. K. Huang, and C. H. Chen, "Barriers to the adoption of ICT in teaching Chinese as a foreign language in US universities," ReCALL, vol. 26, no. 1, pp. 100-116, 2014.

[22] P. Wastiau, R. Blamire, C. Kearney, V. Quittre, E. Van de Gaer, and C. Monseur, "The use of ICT in education: a survey of schools in Europe," European Journal of Education, vol. 48, no. 1, pp. 11-27, 2013.

[23] V. Venkatesh, A. M. Croteau, and J. Rabah, "Perceptions of effectiveness of instructional uses of technology in higher education in an era of Web 2.0," in Proceedings of the 47th Hawaii International Conference on System Sciences (HICSS'2014), pp. 110-119, IEEE, Washington, DC, USA, January 2014.

[24] J. K. Macharia and T. G. Pelser, "Key factors that influence the diffusion and infusion of information and communication technologies in Kenyan higher education," Studies in Higher Education, vol. 39, no. 4, pp. 695-709, 2014.

[25] W. Basri and M. Suliman, "Factors affecting information communication technology acceptance in public organizations in Saudi Arabia," International Journal of Computer Science and Information Security, vol. 10, no. 2, pp. 118-139, 2012.

[26] V. Venkatesh, B. Sue, and H. Bala, "Bridging the qualitative-quantitative divide: guidelines for conducting mixed methods research in information systems," MIS Quarterly, vol. 37, no. 1, pp. 21-54, 2013.

[27] Z. Awang, Structural Equation Modeling Using AMOS, Penerbit Universiti Teknologi MARA, Shah Alam, Selangor Darul Ehsan, Malaysia, 2012.

[28] J. J. Hox and T. M. Bechger, "An introduction to structural equation modelling," Family Science Review, vol. 11, pp. 354-373, 1998.

[29] P.-W. Lei and Q. Wu, "Introduction to structural equation modeling: issues and practical considerations," Educational Measurement Issues and Practice, vol. 26, no. 3, pp. 33-43, 2007.

[30] L.-T. Hu and P. Bentler, "Cutoff criteria for fit indexes in covariance structure analysis: conventional criteria versus new alternatives," Structural Equation Modeling, vol. 6, pp. 1-55, 1999.

[31] M. Hilbert and P. López, "The world's technological capacity to store, communicate, and compute information," Science, vol. 332, no. 6025, pp. 60-65, 2011. 


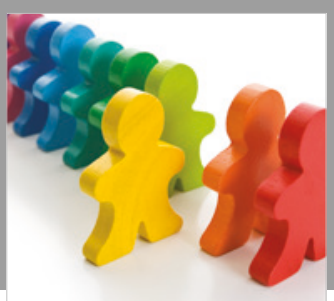

Autism

Research and Treatment
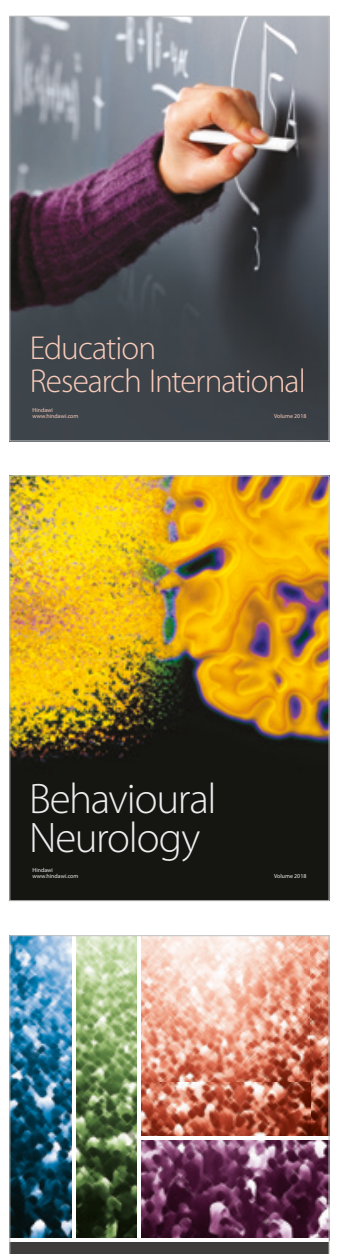

International Journal of

Population Research

$\underline{-m}$

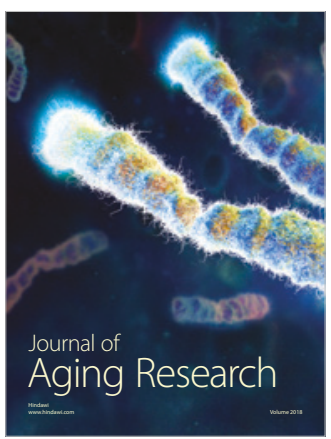

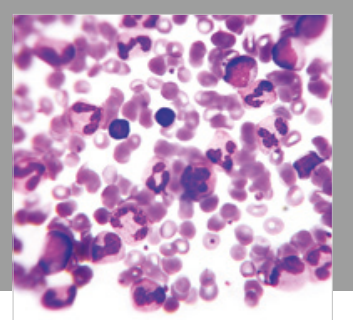

Pathology

Research International$$
=
$$

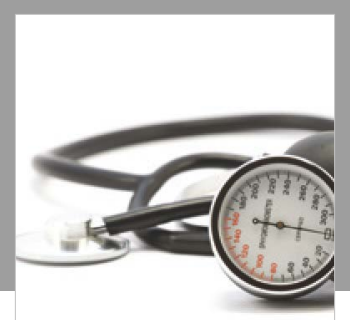

Nursing

Research and Practice

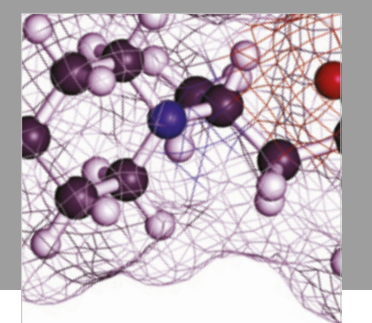

Pain

Research and Management

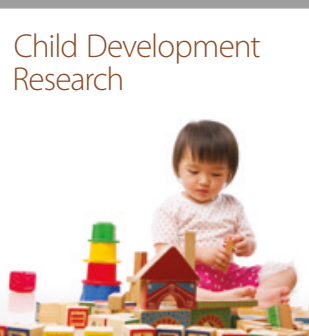

बाD

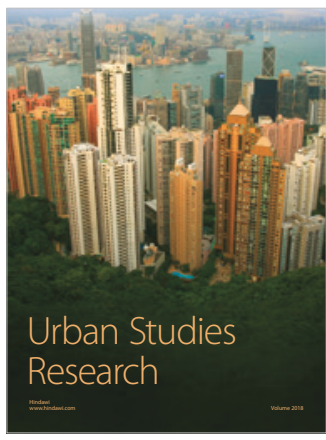

\section{Hindawi}

Submit your manuscripts at

www.hindawi.com
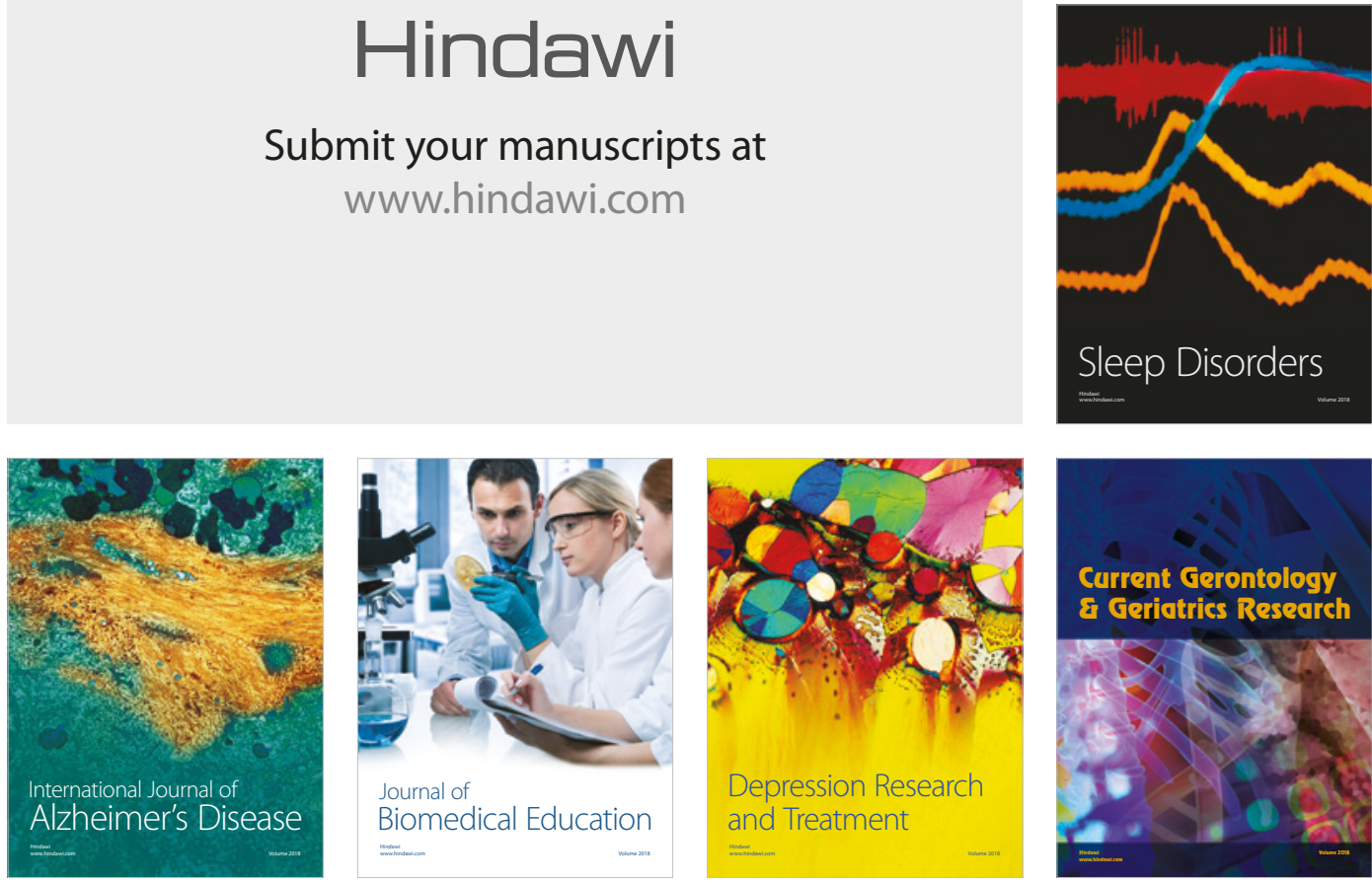

Journal of

Biomedical Education

$=$

smman

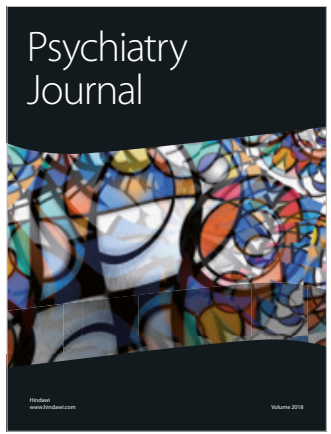

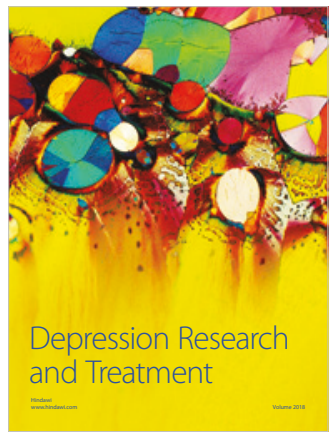
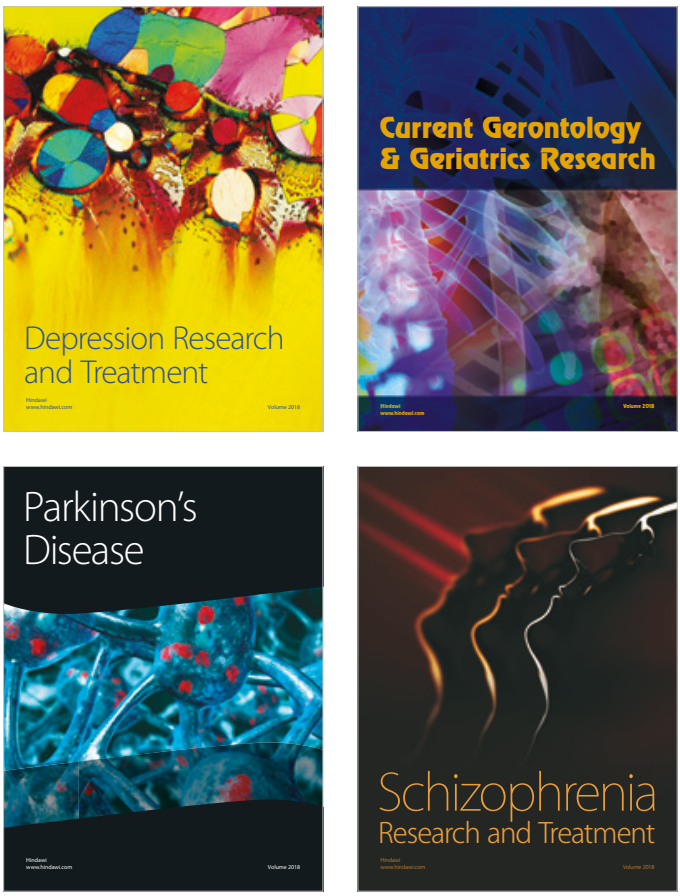